\title{
POTENTIAL FOR REPLACEMENT OF PORTLAND CEMENT BY CERAMIC RESIDUE IN THE SOIL-CEMENT MIXTURE FOR APPLICATION IN PAVING LAYER
}

\author{
André Albino de Sousa ${ }^{1}$ \\ Cinthya Santos da Silva ${ }^{2}$ \\ Robson Arruda dos Santos ${ }^{3}$ \\ Alexandra Amador de Abreu ${ }^{4}$ \\ Leonardo de Souza Dias ${ }^{5}$
}

\begin{abstract}
In 2018, of a total extension of 87,563 kilometers of road network, only $34.2 \%$ of the total presented satisfactory conditions to users. One of the main reasons for this scenario is linked to the high cost of maintenance, including the need for soil stabilization, since the composition of the pavement layers is directly linked to its resistance and durability. In this scenario, the chemical stabilization technique with soil-cement emerges as an alternative for using the soil, which initially did not present corresponding parameters for the respective use. However, the growing demand for replacement of Portland Cement in engineering services, due to the carbon dioxide levels released into the atmosphere during its production, has
\end{abstract}

supported research that deals with the substitution of binder by waste generated by the production sectors, namely, red ceramic waste from the ceramic block industry. This research aims to evaluate the carrying capacity of soils stabilized with cement and the partial replacement by red ceramic waste. Soil characterization tests were carried out, which provided parameters for the dosage of the materials, and subsequent performance of the compaction, expansion and penetration tests. Based on the need to stabilize the soil classified as clayey, group A-7-6, and susceptible to great variation in volume, the addition of $13 \%$ by weight of Portland Cement to the mixture was evaluated and subsequent replacement of the binder in

\footnotetext{
${ }^{1}$ andresousa.ec@gmail.com. Instituto Federal da Paraíba - Campus Cajazeiras.

2 cinthya.santos@ifpb.edu.br. Instituto Federal da Paraíba - Campus Cajazeiras.

${ }^{3}$ robson.santos@ifpb.edu,br. Instituto Federal da Paraíba - Campus Cajazeiras.

${ }^{4}$ Alexandra-abreu@outlook.com.br. Instituto Federal da Paraíba - Campus Cajazeiras.

${ }^{5}$ leonardodiaspb@gmail.com. Universidade Federal do Rio Grande do Norte.
} 
percentages of 20 and $30 \%$. The results demonstrated a reduction in specific mass by increasing the substitution by RCR (Red Ceramic Residue), and also for the expansion presented by the compounds. The CBR test evaluated the percentage of $20 \%$ replacement as the one with the highest load capacity. For paving purposes both percentages of substitution analyzed are within the parameters that satisfy their respective uses in sub-base layers of flexible pavement.

Keywords: Soil-cement. Stabilization. Waste of red ceramic.

\section{INTRODUÇÃO}

Uma das grandes problemáticas que atinge o sistema de transporte rodoviário, principal responsável pela movimentação de cargas e pessoas em todo território brasileiro, é a garantia da qualidade de pavimentação. Em pesquisa realizada no ano de 2018, avaliando as condições de $87.563 \mathrm{~km}$ de rodovias de extensão pública, foi observado que $34,2 \%$ encontram-se em estado ótimo $(4,6 \%)$ ou bom $(29,6 \%)$ enquanto um total de $65,8 \%$ se apresentam como deficientes, sendo classificadas como regulares, ruins ou péssimas. Para entender este panorama é necessário o estudo do serviço de pavimentação como um sistema de camadas responsáveis por absorver e distribuir os esforços causados pelo tráfego, cujo comportamento estrutural depende diretamente da capacidade de suporte do material empregado em cada camada, de suas respectivas espessuras além da interação com demais constituintes do sistema.

Uma vez que a resistência das camadas de pavimentação está diretamente ligada ao material que a constitui, SILVA, aponta uma prática comum a que trata dos solos com baixa capacidade de carga, que comumente são substituídos por materiais com maiores resistências e na grande maioria dos casos descartados. Nesta perspectiva surge um grande desafio no campo da engenharia, que trata do melhoramento do solo através de técnicas de estabilização, seja ela mecânica, química ou granulométrica, executadas por meio de processos de compactação, correção granulométrica ou através de adições de materiais, conferindo ao solo um ganho significativo de resistência às cargas, desgastes e erosão.

No campo de pesquisa da estabilização de solos, a utilização de frações de cimento e cal como material ligante tem se destacado, uma vez que 
promovem reações químicas capazes de facilitar a cimentação dos grãos entre si, modificando propriedades físicas do composto, atribuindo melhores condições das suas propriedades mecânicas.

Embora a utilização desses materiais tenha apresentado resultados satisfatórios, outra grande preocupação que deve ser levada em consideração trata dos impactos ambientais causados pela produção de Cimento Portland. É crescente a demanda de substituição desse material nos serviços de engenharia, uma vez que os índices de dióxido de carbono lançados na atmosfera, durante a produção do Cimento Portland, correspondem de 5 a $8 \%$ da emissão global.

Diferentes pesquisas destacam, ainda, que a porcentagem de cimento empregada no processo de estabilização tem direta influência da porcentagem de material arenoso incorporado ao solo, resultando em volumes cada vez maiores de Cimento Portland para solos predominantemente argilosos, onerando custos além de favorecer o processo de retração e aparecimento de fissuras mediante as propriedades físicas dos materiais supracitados.

Outra grande preocupação que tem embasado o desenvolvimento de estudos trata do aproveitamento de resíduos gerados pelos setores de produção, neste cenário estão inseridos os materiais de cerâmica vermelha, como por exemplo, os tijolos cerâmicos. Durante o processo de produção, ainda realizado de maneira artesanal por empresas de pequeno e médio porte, as medidas de controle tecnológico de produção permitem uma porcentagem de até $30 \%$ de resíduo sobre a produção, como aborda DIAS, quantitativo que se soma ainda a parcela gerada durante o transporte, armazenamento e utilização deste material.

Durante a queima, os blocos moldados são submetidos a temperaturas que variam entre $600^{\circ} \mathrm{C}$ e $800^{\circ} \mathrm{C}$, que transformam o material em uma estrutura sílico-aluminosa amorfa, o que confere a propriedade de pozolana artificial por semelhança de produção, a partir do aumento da superfície ativa do material e da porosidade causada pela instabilidade interna dos argilominerais após a queima. Fatores que colocam o material moído como um elemento cujas propriedades estão dentro das especificadas pela ASTM $618 \mathrm{C}$, que propicia sua utilização em misturas com cimento.

A partir da ideia conjunta de reduzir a utilização de Cimento Portland 
e do aproveitamento de resíduos de cerâmica vermelha, o presente trabalho tem o objetivo de avaliar a capacidade de suporte de carga de misturas de solocimento-resíduo de cerâmica vermelha, estabilizados pelo potencial de reatividade química advindos da substituição parcial nas porcentagens em massa de $20 \%$ e $30 \%$ do Cimento Portland por resíduo. Além de verificar o teor mínimo de cimento para estabilização do solo, de modo a atender especificações técnicas de utilização na execução de camadas de pavimentação.

\section{MATERIAIS E MÉTODOS}

\subsection{Materiais}

\subsection{Solo}

A amostra de solo utilizada na realização dos ensaios foi coletada na cidade de São João do Rio do Peixe, cidade localizada no alto sertão do estado da Paraíba. Na região, o solo apresenta característica argilosa sendo aproveitado principalmente pelo setor da indústria cerâmica na produção de blocos em olarias situadas no município.

A amostra, de aproximadamente três metros cúbicos apresentava um alto índice de torrões, e foi previamente destorroado e quarteado para realização dos ensaios.

\subsection{Cimento Portland}

Foi utilizado na realização dos ensaios o cimento tipo CPV-ARI, que por sua vez não foi submetido a nenhum tipo de ensaio de caracterização, deste modo, as características físicas e químicas consideradas foram às indicadas pelo fabricante.

\subsection{Resíduo cerâmico vermelho \\ O resíduo cerâmico utilizado na} substituição parcial do cimento Portland na presente pesquisa foi obtido na cidade de São João do Rio do Peixe, Paraíba. A coleta foi realizada no pátio da olaria, onde habitualmente fica disposto $\mathrm{o}$ volume de resíduo gerado na produção, transporte e armazenamento do material, que segundo informações fornecidas pelo setor de produção, contabilizam perdas de aproximadamente $550 \mathrm{~kg} / \mathrm{semana}$.

O RCV passou por um processo de beneficiamento com a finalidade de reduzir a granulometria do material até adquirir a finura adequada. Com o auxílio de um triturador, foi realizada a moagem previa do material que em seguida seguiu para o trituramento manual com auxílio de um soquete. O processo de beneficiamento foi encerrado com o peneiramento do RCV, descartando o material retido na peneira $\mathrm{ABNT} \mathrm{n}^{\circ} 200$ (abertura de 0,0075mm). 
A finura do material utilizado na realização desta pesquisa tomou como base bibliografias que associam $\mathrm{o}$ aumento da área específica do material à atividade pozolânica apresentada pelo mesmo, a saber, do estudo realizado por MEDEIROS et. al. e GARCIA et. al.

\subsection{Métodos}

\subsection{Caracterização do solo e do} resíduo

A análise granulométrica conjunta de peneiramento e sedimentação do solo a ser utilizado para a mistura solo-cimento foi realizada conforme ABNT NBR 7181, cujas amostras foram preparadas de acordo com a ABNT NBR 6457. O ensaio de determinação da massa específica dos grãos seguiu as determinações da ABNT NBR 6458, em ressalva a utilização de apenas uma amostra de solo passante na peneira de abertura $4,8 \mathrm{~mm}$ mantida em defloculante por um período de 24 horas.

Os ensaios de limite de liquidez e plasticidade foram realizados com uma amostra de solo passante na peneira $n^{\circ}$ 40, seguindo as determinações da ABNT NBR 6459 e ABNT NBR 7180, respectivamente.

Para avaliar a composição química da amostra de resíduo cerâmico vermelho foi utilizado o método de Espectrometria de fluorescência de raios
X.

Por fim, o ensaio de compactação foi realizado com uma amostra de solo passante na peneira $\mathrm{ABNT}^{\circ}$ 4, preparas de acordo com a ABNT NBR 6457, seguindo as determinações da ABNT NBR 12023, que ressalta dois métodos para a realização do experimento de acordo com as características granulométricas do solo, onde foi adotado o método $\mathrm{B}$, para solos com até $30 \%$ de partículas com diâmetro superior a $19 \mathrm{~mm}$. O ensaio foi realizado para cinco diferentes teores de umidade, sem reuso de material,

\subsection{Determinação da dosagem de cimento e RCV}

Conhecidas a caracterização do solo, de acordo com o sistema AASHTO, o método de dosagem utilizado na presente pesquisa se baseia no Manual de laboratório de solo-cimento da PCA, uma vez que a ABNT se mantem conservadora quanto à utilização para fins de estabilização de solos argilosos, por sua vez não contemplados na $\mathrm{ABNT}$ NBR 12253. Ao comparar as metodologias apresentadas é possível observar uma pequena variação nos teores de cimento a serem incorporados à mistura possível, o que de acordo com a ABCP, não produz uma variação 
significante diante da análise dos resultados.

Para fins de redução do consumo de cimento nas misturas foram analisadas as porcentagens de $20 \%$ e $30 \%$ de substituição em massa do aglomerante por resíduo cerâmico, que tiveram como base a pesquisa realizada por DALLACORT et. al., levando em consideração os parâmetros de umidade, massa específica e teor de ligante do composto.

\subsection{Determinação da capacidade}

\section{de suporte de carga do material}

O ensaio de Índice de Suporte Califórnia (ISC), seguiu as orientações da ABNT NBR 9895, com ressalva da moldagem dos corpos de prova apenas nas condições de umidade ótima, esta por sua vez obtida pelo ensaio de compactação das misturas, seguindo as recomendações da ABNT 12023. Para a porcentagem de água adicionada a fim de que a umidade de compactação se aproximasse a umidade ótima foi considerada a umidade higroscópica do solo, além de adotar o cimento e RCV utilizados como materiais totalmente secos.

Após a moldagem, foram realizadas leituras de expansão a cada 24h de imersão durante um período de quatro dias. Posteriormente os corpos de provas foram emersos e submetidos ao ensaio de penetração, por sua vez, foi realizado com o auxílio de uma prensa, registrando as cargas aplicadas a cada intervalo conforme a supracitada NBR orienta.

\section{RESULTADOS E DISCUSSÕES}

\subsection{Caracterização do solo}

Os ensaios de análise granulométrica, cujos resultados são apresentados na tabela 1, permitiram caracterizar o solo de acordo com as porcentagens de materiais passantes no conjunto de peneiras normatizadas pela abnt, e de maneira conjunta a análise dos finos pelo método de sedimentação. esta análise permitiu ainda a determinação da curva granulométrica do solo, conforme figura 1 .

Tabela 1: Caracterização granulométrica do solo.

\begin{tabular}{l|l}
\hline COMPOSIÇÃO & DIÂMETRO DAS PARTÍCULAS \\
\hline Massa específica dos sólidos & $2,64\left(\mathrm{~g} / \mathrm{cm}^{3}\right)$ \\
\hline Limite de liquidez & $57(\%)$ \\
\hline Limite de plasticidade & $16(\%)$ \\
\hline Índice de plasticidade & $41(\%)$ \\
\hline
\end{tabular}




\begin{tabular}{l|l}
\hline Pedregulho & $0(\%)$ \\
\hline Areia grossa & $16,8(\%)$ \\
\hline Areia média & $1,6(\%)$ \\
\hline Areia fina & $14,9(\%)$ \\
\hline Silte & $34,7(\%)$ \\
\hline Argila & $32(\%)$ \\
\hline Classificação AASHTO & A-7-6 \\
\hline Classificação SUCS & CH \\
\hline
\end{tabular}

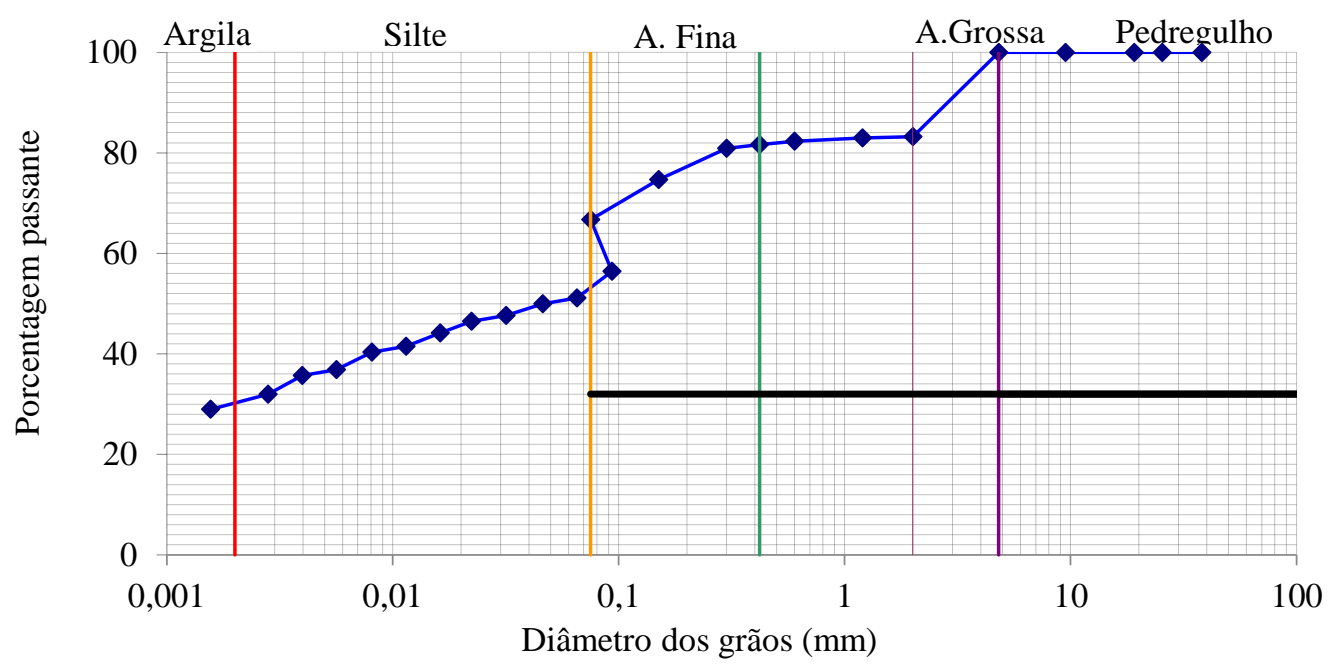

Figura 1: Curva granulométrica.

Os limites de liquidez, plasticidade e índice de plasticidade foram de 57, 16 e $41 \%$, respectivamente. A caracterização granulométrica mostrou que se trata de um solo argiloso de alta plasticidade, cujo percentual de argila e silte correspondem a uma porcentagem de $66,7 \%$.

A descontinuidade apresentada na curva granulométrica da Figura 1 ocorre devido à sobreposição dos ensaios de peneiramento e sedimentação, MANSO esta irregularidade pode ser atribuída a porcentagem argilomineral presente na fração granulométrica que nem sempre são desagregadas pela ação do defloculante.

A Tabela 1 apresenta ainda a classificação do solo de acordo com o sistema AASHTO e SUCS, cujos resultados obtidos estão conforme especificações do manual DNIT.. As informações serviram como base teórica para determinação da porcentagem de cimento a ser adicionada à amostra, conforme Manual de laboratório de solocimento da PCA, a fim de garantir propriedades de utilização rodoviária. 
Foi definida uma adição percentual de $13 \%$ em massa de Cimento Portland ao solo analisado. $\mathrm{O}$ alto teor de aglomerante a ser adicionado é justificado por bibliografias como FREIRE e ABCP devido à porcentagem de argila presente. Os resultados apresentados corroboram a análise apresentada por GOMES, para um solo cuja classificação do tipo A-7-6.

O ensaio de determinação da massa específica do solo apresentou um resultado de $2,64 \mathrm{~g} / \mathrm{cm}^{3}$, valor dentro das especificações do Manual de pavimentação DNIT para materiais com potencial de utilização em pavimentação rodoviária, que varia entre 2,6 e 2,8 $\mathrm{g} / \mathrm{cm}^{3}$. Já no que trata dos valores máximos fixados para o limite de liquidez e índice de plasticidade pelo supracitado manual, que são de 25 e $6 \%$ respectivamente, o solo analisado não de adequa por apresentar percentuais superiores, justificados pelo alto teor de finos presentes no material.

\subsection{Caracterização do resíduo} cerâmico

A composição química do resíduo de cerâmica vermelha foi obtida através da análise de espectrometria de fluorescência de raios x (frx), cujos resultados são apresentados na tabela 2

\begin{tabular}{l|l}
\hline ÓXIDOS & TEOR (\%) \\
\hline $\mathrm{SiO} 2$ & 57,084 \\
\hline $\mathrm{Fe} 2 \mathrm{O} 3$ & 21,549 \\
\hline $\mathrm{A} 2 \mathrm{O} 3$ & 8,401 \\
\hline $\mathrm{K} 2 \mathrm{O}$ & 5,860 \\
\hline $\mathrm{CaO}$ & 3,838 \\
\hline $\mathrm{TiO} 2$ & 2,308 \\
\hline $\mathrm{MnO}$ & 0,266 \\
\hline $\mathrm{ZrO} 2$ & 0,187 \\
\hline
\end{tabular}

Tabela 2: caracterização química do RCV

É possível observar que os óxidos $\mathrm{SiO}_{2}, \mathrm{Al}_{2} \mathrm{O}_{3}$ e $\mathrm{Fe}_{2} \mathrm{O}_{3}$ somam $87,03 \%$, valor superior ao percentual mínimo de $70 \%$ estipulado para pozolanas naturais e artificiais apresentado pela ABNT NBR 12653.
Entretanto, o teor de $\mathrm{K}_{2} \mathrm{O}$ foi de $5,86 \%$, acima do teor máximo de $1,5 \%$, não atendendo as especificações químicas mínimas para caracterizar a fração de resíduo de cerâmica vermelha como material pozolânico. Os resultados 
obtidos a partir do ensaio de espectrometria, a saber, do elevado teor de $\mathrm{K}_{2} \mathrm{O}$ se apresentaram compatíveis à análise apresentada por FAGUNDES.

\subsection{Ensaios de compactação}

Na tabela 3 são apresentados os resultados referentes aos ensaios de compactação realizados da mistura base, cujo percentual de cimento adicionado é de $13 \%$ e das misturas com substituição percentual do aglomerante em porcentagens de 20 e $30 \%$. A tabela apresenta respectivamente a denominação das misturas, massas específicas secas máximas e umidades ótimas para cada mistura analisada.

\begin{tabular}{l|l|l}
\hline MISTURA & $\rho_{\text {mÁx }}\left(\mathbf{G} / \mathbf{C M}^{3}\right)$ & $W_{\text {ótima }}(\%)$ \\
\hline SC (0\% RCV) & 1,637 & 16,2 \\
\hline SC (20\% RCV) & 1,613 & 17,8 \\
\hline SC (30\% RCV) & 1,608 & 18,1 \\
\hline
\end{tabular}

Tabela 3: resultados do ensaio de compactação

As curvas de compactação, representações gráficas dos dados apresentados na tabela 3, referentes às amostras analisadas, são apresentadas na figura 2. Uma vez que a curva de compactação apresenta tendência polinomial de grau dois, vale ressaltar que os coeficientes de determinação $\left(\mathrm{r}^{2}\right)$ foram de respectivamente $0,987,0,990 \mathrm{e}$ 0,978 indicando uma ótima assertividade do ensaio diante da função de ajuste. 


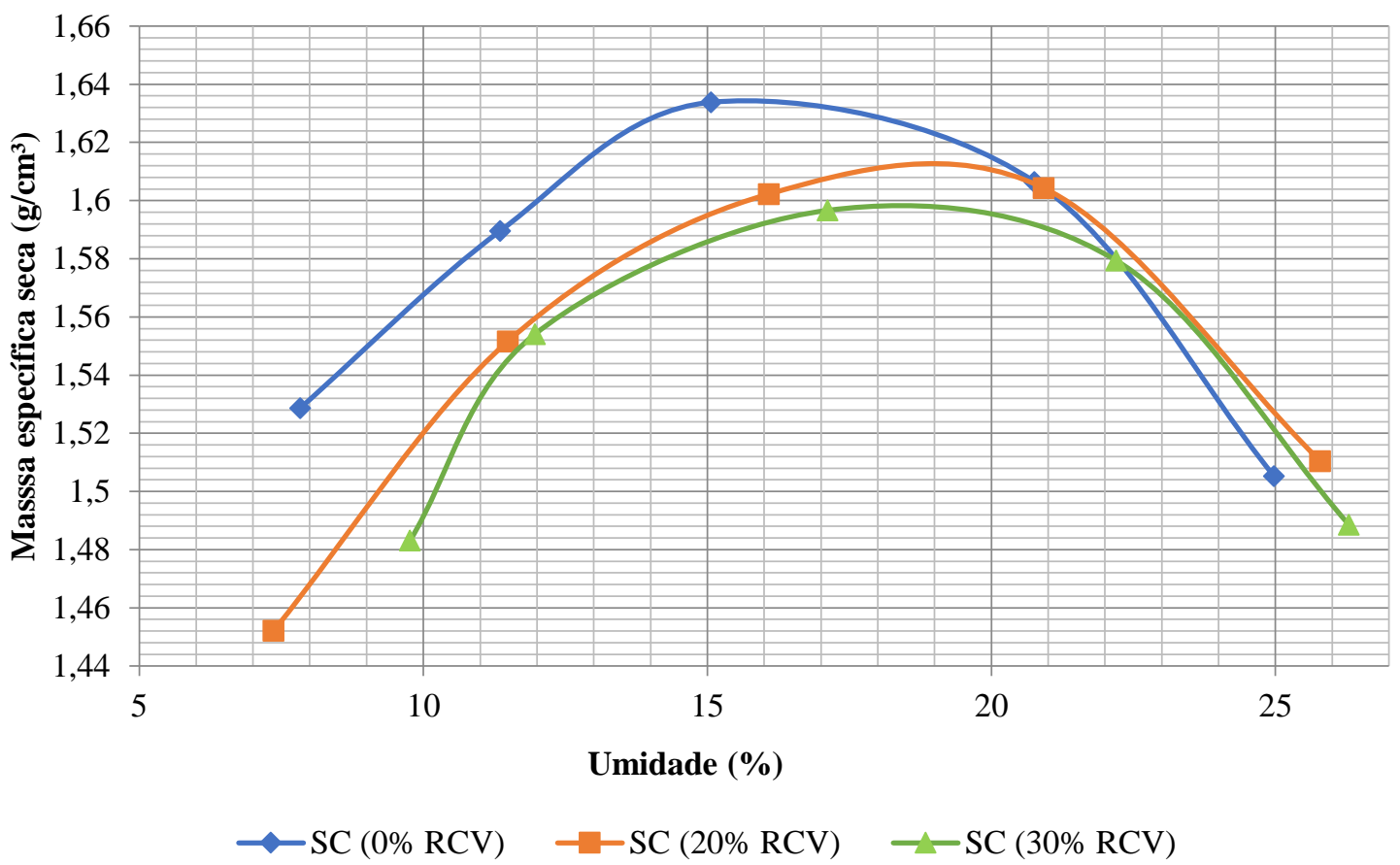

Figura 2: Curvas de compactação.

$\mathrm{Na}$ Figura 2 nota-se um deslocamento das curvas para a direita referentes às amostras acrescidas de resíduo cerâmico. COSTA et. al., verifica este comportamento em sua pesquisa devido ao aumento na quantidade de finos do material e consequente aumento na absorção de água. No que trata da diminuição da massa específica seca observada com esse deslocamento das curvas, esta pode ser atribuída a maior necessidade de água para envolver completamente as superfícies de contato das partículas mais finas.

\subsection{Ensaios de Índice de Suporte Califórnia (ISC)}

Conhecidas as massas específicas secas máximas e umidades ótimas para cada amostra foram realizados os ensaios de cbr. os resultados são apresentados na tabela 4 acompanhados das respectivas condições de moldagens dos corpos de prova

\begin{tabular}{l|l|l|l|l}
\hline MISTURA & $\begin{array}{l}W_{\text {mold }} \\
(\%)\end{array}$ & $\begin{array}{l}\rho_{\text {mold }} \\
\left(\mathbf{G} / \mathbf{C M}^{3}\right)\end{array}$ & CBR (\%) & EXPANSÃO \\
\hline $\mathrm{SC}(0 \% \mathrm{RCV})$ & 16,5 & 1,64 & 33,19 & 0,36 \\
\hline $\mathrm{SC}(20 \% \mathrm{RCV})$ & 17,2 & 1,60 & 37,16 & 0,35 \\
\hline $\mathrm{SC}(30 \% \mathrm{RCV})$ & 17,7 & 1,58 & 35,06 & 0,28 \\
\hline
\end{tabular}


Tabela 4: Resultados do ensaio de Compactação.

Os valores de umidade de moldagem e massa específica seca de moldagem apresentados, foram obtidos a partir da média aritmética entre três as amostras recolhidas durante a compactação dos corpos de prova. Durante a análise, o desvio padrão entre os respectivos dados analisados não superaram $10 \%$ garantindo a representatividade dos valores médios.

Verifica-se que o comportamento das misturas compactadas foi similar aos obtidos nos ensaios de compactação anteriormente mencionados, destaca-se que a diferença entre os parâmetros ótimos quando comparados aos de moldagem está na dificuldade de controle da umidade do solo que está sendo compactado e da energia de compactação. DALLACORT et. al. destaca que as supracitadas diferenças se tornam significativas quando superiores a $2 \%$, valor superior ao observado nesta pesquisa.

Ao analisar a Tabela 4 nota-se que a composição de substituição de $20 \%$ de Cimento Portland resultou em um CBR de $37,16 \%$, um incremento de $8,93 \%$ na capacidade de suporte de carga em comparação a dosagem base sem adição percentual de resíduo. A Figura 4 apresenta a curva obtida com a realização do ensaio de ISC para a mistura base de solo-cimento sem adição de RCV 


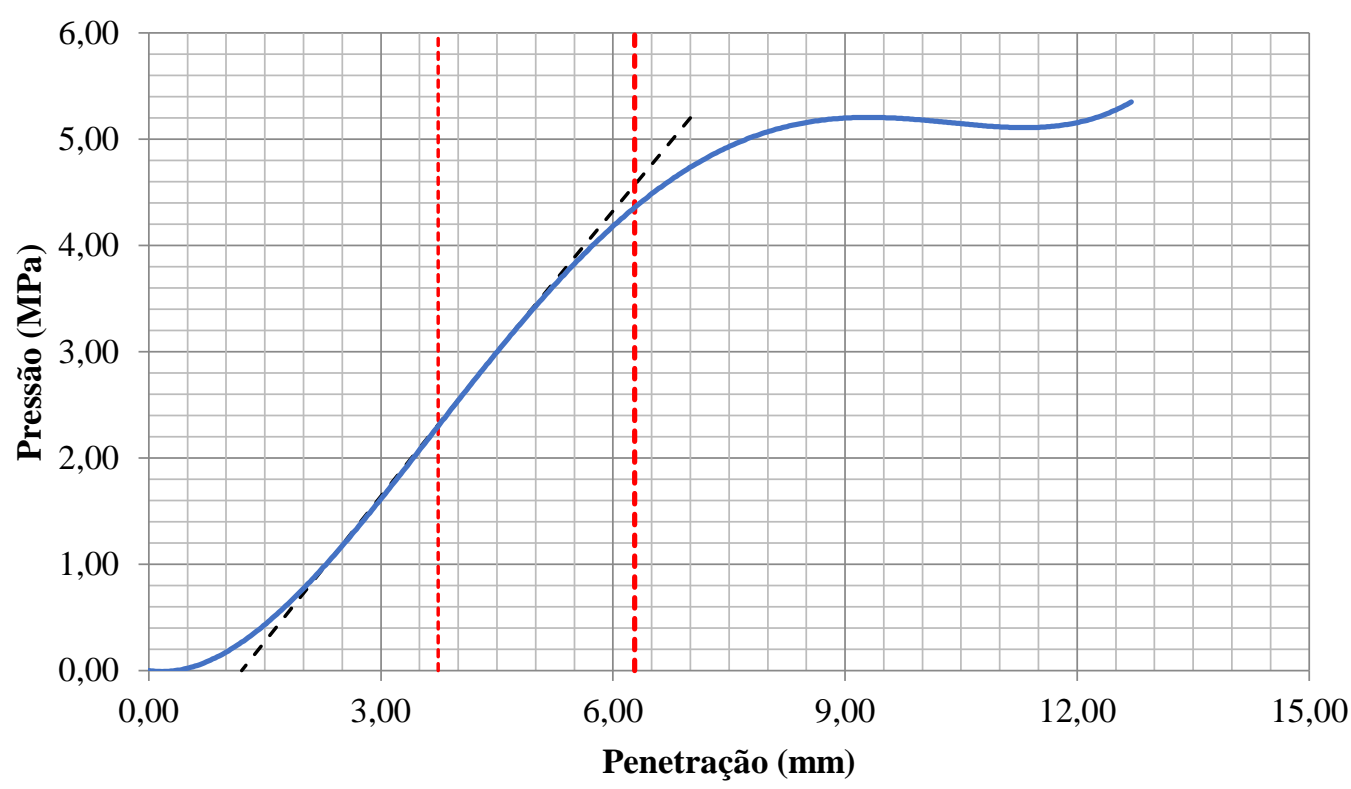

- - - Reta tangente de correção - - --. 3,74 mm - - - 6,28 mm - SC (0\% RCV)

Figura 3: Curva de ISC para a mistura SC ( $0 \%$ RCV).

Para a curva da Figura 3, devido à inflexão apresentada, foi necessária a utilização de um fator de correção, que segundo a ABNT NBR 9895 é determinado pelo ponto em que uma reta tangente ao ponto de inflexão toca o eixo das abcissas. Este comportamento do gráfico se apresenta devido irregularidades na superfície do corpo de prova ou ainda à variação da velocidade aplicada durante o ensaio, fator facilmente registrado na execução de experimentos em equipamentos manuais. A correção propiciou o deslocamento das penetrações padrão em 1,2 mm justificando a capacidade de 33,19\% apresentada na Tabela 4.

SILVA afirma que, geralmente, os maiores valores de CBR se apresentam nos materiais de maior massa específica seca máxima. Entretanto foi observado que o maior valor registrado de CBR resultou da mistura cuja massa específica mencionada apresenta-se em posição intermediária. Este comportamento é analisado por SOUZA et. al. como uma consequência a adição de finos a mistura, que reduz a massa específica do composto. Por sua vez, DALLACORT et. al., cujos resultados são similares aos verificados nesta pesquisa no que trata do teor ótimo de aglomerante substituído por RCV, ainda atribui à atividade cimentante do material ligante e à presença do RCV, com um efeito de microfiller, a formação de um esqueleto 
sólido composto entre os grãos de solo e finos. curvas de ISC para as porcentagens de substituição de Cimento Portland.

$\mathrm{Na}$ Figura 4 são apresentadas as

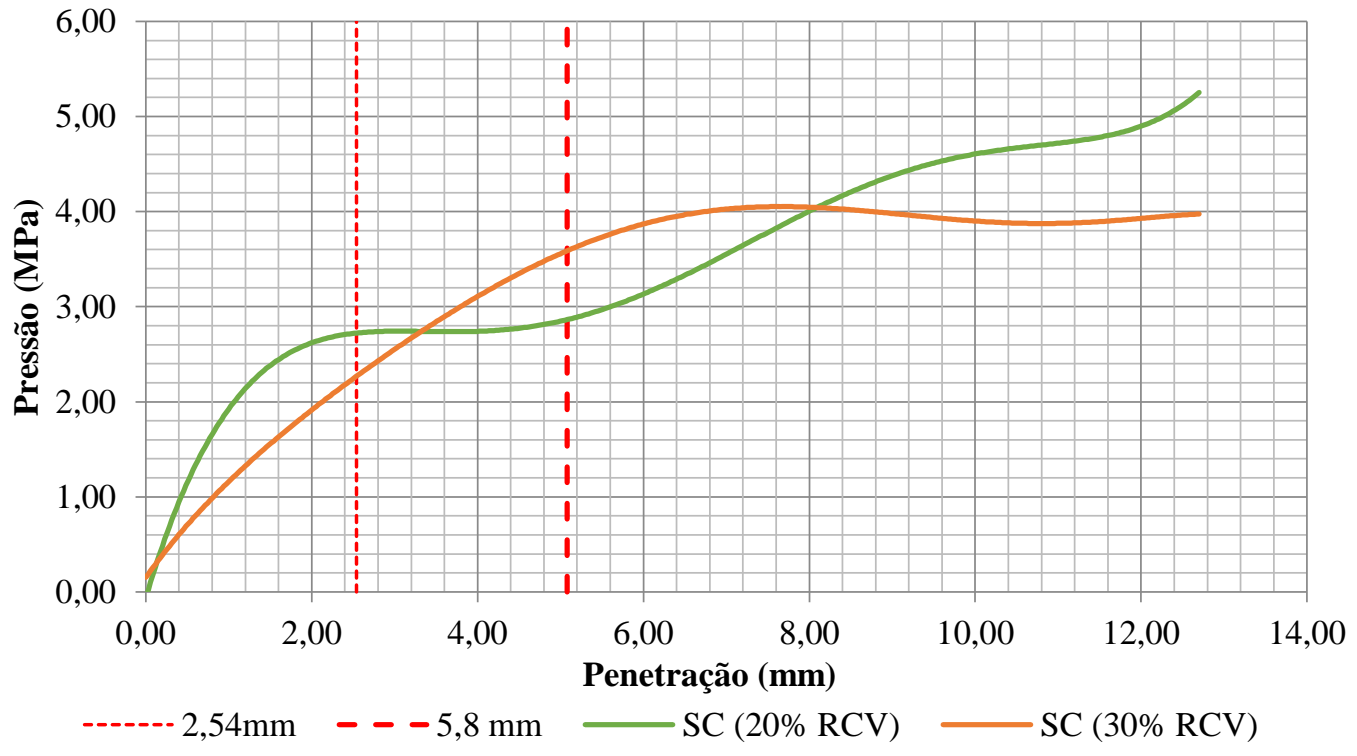

Figura 4: Curva de ISC para as misturas com substituição de cimento.

A Figura 4 evidencia a discreta perda da capacidade de suporte quando se substitui em $30 \%$ o teor de aglomerante da mistura. Por sua vez, a Figura 5, que apresenta a curva de expansão dos compostos, onde é possível observar uma queda no percentual de expansão diante do aumento do teor de RCV adicionado. 


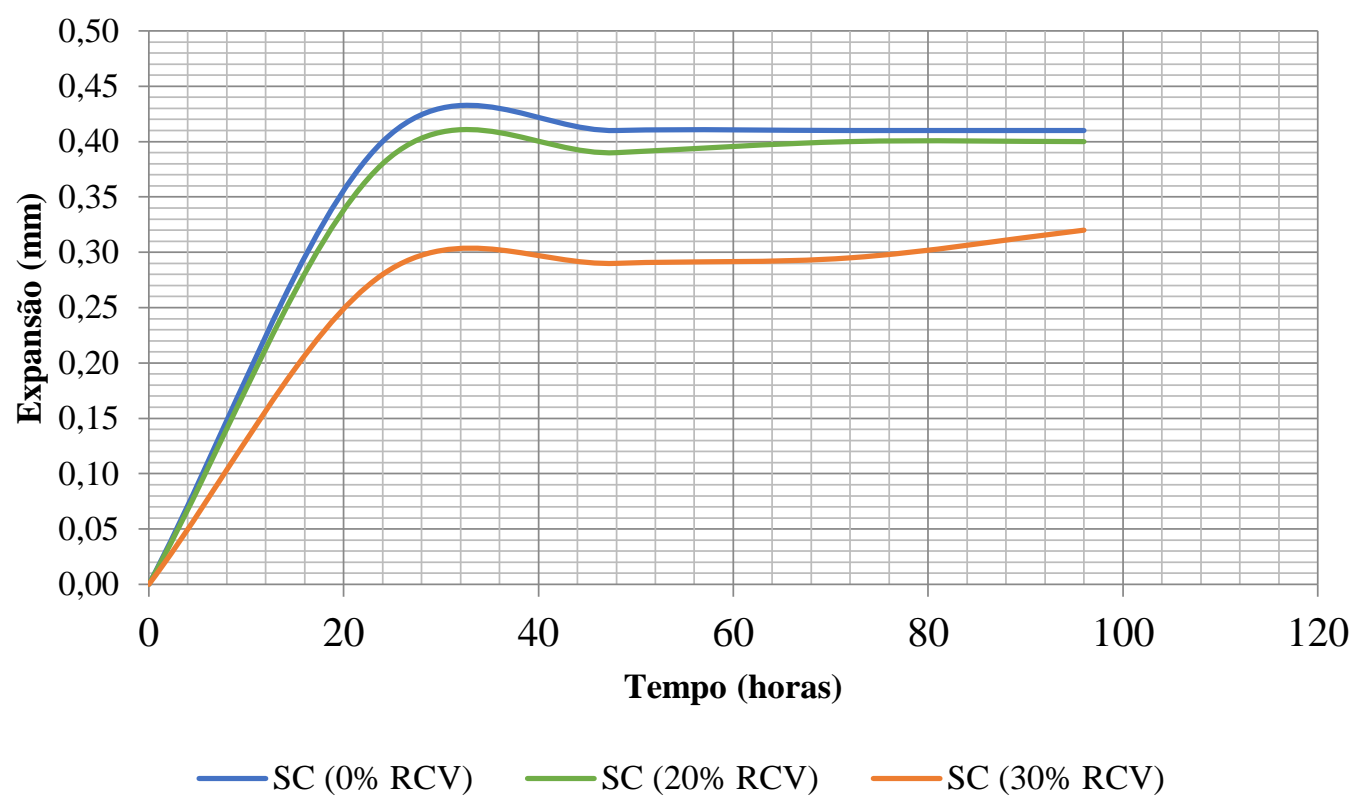

Figura 5: Curvas de expansão.

Verifica-se que o maior valor de expansão obtido foi de $0,36 \%$ para a mistura de solo cimento sem substituição mostrando que os valores obtidos classificam as misturas como pouco expansivas. É possível então perceber um melhoramento do solo natural anteriormente caracterizado como sujeito a grandes variações de volume diante de seus elevados limite de liquidez e índice de plasticidade. As informações apresentadas para o ensaio de expansão são semelhantes aos dados encontrados por JOAQUIM para um solo argiloso estabilizado com cimento para fins de pavimentação.

\section{CONCLUSÃO}

A caracterização da amostra de solo utilizada apresentou uma porcentagem superior a $60 \%$ de material passante na peneira $\mathrm{n}^{\circ} 200$ (abertura $0,0075 \mathrm{~mm}$ ) o que caracteriza uma alta porcentagem de finos, em maior quantidade silte, seguido por argila e areia. $\mathrm{O}$ solo foi classificado de acordo com o sistema AASHTO como argiloso, sujeito a altas variações de volume devido aos elevados limite de liquidez e índice de plasticidade, fatores que inviabilizam sua aplicação em camadas de pavimentação conforme especificações DNIT.

A partir da caracterização do solo natural foi possível realizar a dosagem das misturas, que conforme Manual de laboratório de solo-cimento da PCA, devem ser estabilizadas com uma 
porcentagem de $13 \%$ de Cimento Portland em massa, que por sua vez foi ainda substituído parcialmente por resíduo cerâmico vermelho nas porcentagens de 20 e $30 \%$. O ensaio de caracterização realizado com o resíduo cerâmico apresentou um somatório de $87,03 \%$ de sua composição por $\mathrm{SiO}_{2}$, $\mathrm{FeO}_{3}$ e $\mathrm{Al}_{2} \mathrm{O}_{3}$, porém devido o teor de $\mathrm{K}_{2} \mathrm{O}$, da ordem de $5,86 \%$ o material não pode ser caracterizado como pozolânico, conforme ABNT NBR 12653 por sua vez sendo observada sua atuação como microfiller, preenchendo os vazios da mistura e conferindo um aumento de resistência ao composto

Observou-se que as adições de resíduo ocasionam um decréscimo da massa específica seca máxima e um consequente aumento da umidade ótima das amostras, justificadas mediante o aumento da porcentagem de finos da mistura.

A partir da análise de penetração e expansão através do ensaio de ISC, temse o resultado de máximo suporte de carga para a mistura solo-cimento com substituição do aglomerante em porcentagem de $20 \%$ apresentando $37,16 \%$ e $0,35 \%$ de CBR e expansão, respectivamente.

Não obstante o resultado insatisfatório obtido para a mistura de solo-cimento com percentual de substituição de $30 \%$ foi possível observar um ganho na capacidade de suporte quando comparado à mistura base, o que comprova o efeito positivo da substituição do aglomerante por RCV. Os presentes resultados permitem concluir que o teor de $20 \%$ de RCV em substituição do cimento Portland está ligado a maior capacidade de carga analisada. Entretanto, ao se tratar da potencialidade de substituição do Cimento Portland por resíduo cerâmico vermelho, foi possível observar que embora oferecendo uma capacidade de carga discretamente inferior a máxima observada nesta pesquisa, o teor de substituição de $30 \%$ de cimento Portland por resíduo cerâmico vermelho apresenta-se dentro dos parâmetros para utilização em camadas de sub-base de pavimentos flexíveis conformes especificações do Manual de Pavimentação DNIT.

\section{BIBLIOGRAFIA}

AMERICAN SOCIETY OF TESTING AND MATERIALS. ASTM 618C: Fly ash and raw or calcined natural pozzolan for use as mineral admixture in Portland cement concrete. Philadelphia, 2019.

ARCANJO, D. M. O. "Estudo da aplicação de aglomerantes álcali- 
ativados na estabilização de solos para pavimentações". Dissertação de Mestrado em Engenharia Civil, Universidade Federal da Bahia. Salvador, 2018.

ASSOCIAÇÃO BRASILEIRA DE CIMENTO PORTLAND - ABCP.

Dosagem das misturas de solo-cimento: Normas de dosagem e métodos de ensaio. 2004.

ASSOCIAÇÃO BRASILEIRA DE NORMAS TÉCNICAS - ABNT. NBR 12023: Solo-cimento - Ensaio de compactação. Rio de Janeiro, 2012.

ASSOCIAÇÃO BRASILEIRA DE NORMAS TÉCNICAS - ABNT. NBR 12253: Solo-cimento - Dosagem para emprego como camada de pavimento. Rio de Janeiro, 2012.

ASSOCIAÇÃO BRASILEIRA DE NORMAS TÉCNICAS - ABNT. NBR 6457: Amostras de solo - Preparação para ensaios de compactação e ensaios de caracterização. Rio de Janeiro, 2016. ASSOCIAÇÃO BRASILEIRA DE NORMAS TÉCNICAS - ABNT. NBR 6458: Grãos de pedregulho retidos na peneira de abertura 4,8 $\mathrm{mm}$ Determinação da massa específica, da massa específica aparente e da absorção de água. Rio de Janeiro, 2016.

ASSOCIAÇÃO BRASILEIRA DE NORMAS TÉCNICAS - ABNT. NBR
6459: Solo - Determinação do limite de liquidez. Rio de Janeiro, 2016.

ASSOCIAÇÃO BRASILEIRA DE NORMAS TÉCNICAS - ABNT. NBR 7180: Solo - Determinação do limite de plasticidade. Rio de Janeiro, 2016.

ASSOCIAÇÃO BRASILEIRA DE NORMAS TÉCNICAS - ABNT. NBR 7181: Solo - Análise granulométrica. Rio de Janeiro, 2016.

ASSOCIAÇÃO BRASILEIRA DE NORMAS TÉCNICAS - ABNT. NBR 9895: Solo - Índice de suporte Califórnia. Rio de Janeiro, 2016.

ASSOCIAÇÃO BRASILEIRA DE NORMAS TÉCNICAS - ABNT. NBR12653: Materiais pozolânicos Requisitos. Rio de Janeiro, 2014.

BERNUCCI, L. B; MOTTA, L. M. G; CERATI, J. A. P; SOARES, J. B., "Pavimentação asfáltica: formação básica para engenheiros". Petrobras: ABEDA, 2006.

CNT; SEST; SENAT. "Pesquisa CNT de rodovias 2018: relatório gerencial. Brasília”. Disponível em: https://pesquisarodovias.cnt.org.br/edic oes. Acesso em: 03 out. 2019.

COSTA, E. V. L.; SILVA, E. C. G.; RÊGO, M.C. Q. "Influência da fração vermelha do resíduo de construção civil com cal na estabilização de um solo da formação Guabirotuba para 
pavimentação". Trabalho de Conclusão de Curso, Universidade Tecnológica Federal do Paraná, Paraná, 2018.

DALLACORT, R. et al. "Resistência à compressão do solo-cimento com substituição parcial do cimento Portland por resíduo cerâmico moído". Revista Brasileira de Engenharia Agrícola e Ambiental, Campina Grande, v. 6, n. 3, p. 511-518, 2002.

DEPARTAMENTO NACIONAL DE INFRAESTRUTRA DE TRANSPORTES - DNIT. Manual de Pavimentação. $3^{\mathrm{a}}$ ed. Rio de Janeiro. 2006.

DEPARTAMENTO NACIONAL DE INFRAESTRUTRA $\mathrm{DE}$ TRANSPORTES - DNIT. Norma 172: Solos - Determinação do Índice de Suporte Califórnia utilizando amostras não trabalhadas - Método de ensaio. Brasília. 2016.

DIAS, J. F. "Avaliação de resíduos da fabricação de telhas cerâmicas para seu emprego em camadas de pavimento de baixo custo". Tese de Doutorado, Escola Politécnica da Universidade de São Paulo, São Paulo, 2004.

FAGUNDES, L. P. "Utilização de resíduo de cerâmica proveniente de olarias para estabilização de solo laterítico". Dissertação de Mestrado em
Engenharia Civil, Universidade Estadual Paulista, Ilha Solteira, 2019.

FREIRE, W. J. “Tratamento prévio do solo com aditivos químicos e seu efeito sobre a qualidade do solo-cimento". Tese de Doutorado, Escola Superior de Agricultura "Luiz de Queiroz", Universidade de São Paulo, Piracicaba, 1976.

GOMES, T. H. “Análise da resistência a compressão simples de um solo argiloso artificialmente cimentado". Trabalho de Conclusão de Curso, Universidade Federal de Campina Grande, 2019.

GARCIA, E., CABRAL JUNIOR, M., QUARCIONI, V. A., et al. "Resíduo de cerâmica vermelha (RCV): uma alternativa como material pozolânico". Revista Cerâmica Industrial, v. 19, n. 4, pp. 31 - 38, Julho/Agosto 2014.

JOAQUIM, A. G.1 et al. "Estudo de dois solos tropicais melhorados com cimento ou cal para emprego em camadas superiores de estradas não pavimentadas". Dissertação de Mestrado em Engenharia civil na área de transportes, Universidade Estadual de Campinas, Campinas, 2017.

MANSO, E. A. “Análise granulométrica dos solos de Brasília pelo granulômetro a laser". Tese de Doutorado, Universidade de Brasília, Brasília, 1999. 
MEDEIROS, M. H. F. de et al. "Resíduo de cerâmica vermelha e fíler calcário em compósito de cimento Portland: efeito no ataque por sulfatos e na reação álcalisílica”. Matéria (Rio de Janeiro), v. 21, n. 2, p. 282-300, 2016.

PORTLAND

CEMENT

ASSOCIATION - PCA. Soil-cement laboratory handbook. Portland Cement Assoc., 1992

RIOS, S.; CRISTELO, N.; DA FONSECA, A.V.; FERREIRA, C. "Stiffness behavior of soil stabilized with alkali-activated fly ash from small to large strains". International Journal of Geomechanics, n. 04016087, 2017.

RIOS, S.; CRISTELO, N.; DA FONSECA, A.V.; FERREIRA, C. "Structural performance of alkali activated soil ash versus soil cement". Journal of Materials in Civil Engineering, n. 04015125, 2016.
SILVA, P. B. "Estabilização de misturas de resíduos sólidos de demolição e da indústria cerâmica para uso em camadas de pavimentos de vias". Tese de Doutorado em Engenharia de Transportes, Escola Politécnica da Universidade de São Paulo, São Paulo, 2014.

SILVA, J. P. S.; CARVALHO, S. B. "Uso de resíduos de cerâmica vermelha para o melhoramento de camadas de pavimentos de baixo tráfego em PalmasTO”. Revista Eletrônica de Gestão $e$ Tecnologias Ambientais, v. 5, n. 1, p. 4152, 2017.

SOUZA, W. M. et al. "Resíduos de cerâmica vermelha como um material ambientalmente sustentável para uso na pavimentação". Revista Eletrônica de Gestão e Tecnologias Ambientais, v. 7 , n. 2, p. 202-213, 2019 